\title{
Direct and simultaneous determination of trace-level carbon tetrachloride, peroxyacetyl nitrate, and peroxypropionyl nitrate using gas chromatography-electron capture detection
}

\author{
Gen Zhang ${ }^{\mathrm{a}}$, Yujing Mu ${ }^{\mathrm{a}, *}$, Junfeng Liu ${ }^{\mathrm{a}}$, Abdelwahid Mellouki ${ }^{\mathrm{b}, * *}$ \\ a Research Center for Eco-Environmental Sciences, Chinese Academy of Sciences, Beijing 100085, China \\ ${ }^{\mathrm{b}}$ Centre National de Recherche Scientifique-Institut de Combustion, Aérothermique, Réactivité et Environnement (CNRS-ICARE) and OSUC, 45071 Orléans Cedex 02, France
}

\section{A R T I C L E I N F O}

\section{Article history:}

Received 5 July 2012

Received in revised form

21 September 2012

Accepted 24 September 2012

Available online 2 October 2012

\section{Key words:}

Peroxyacetyl nitrate

Peroxypropionyl nitrate

Capillary column

GC-ECD

Detection

\begin{abstract}
A B S T R A C T
Gas chromatography equipped with electron capture detector (GC-ECD) has been widely used for detecting atmospheric peroxyacetyl nitrate (PAN) and peroxypropionyl nitrate (PPN). However, to the best of our knowledge, only a few capillary columns have been adopted for separation to achieve the direct and simultaneous analysis of the two atmospheric pollutants. This paper demonstrates a novel method for directly and simultaneously measuring atmospheric carbon tetrachloride $\left(\mathrm{CCl}_{4}\right), \mathrm{PAN}$, and PPN using GC-ECD with a DB-1 separation column. The responses of the GC-ECD to PAN, PPN, and $\mathrm{CCl}_{4}$ were individually calibrated by using gas mixtures prepared via volatilization of synthesized solutions of PAN and PPN or high-purity $\mathrm{CCl}_{4}$ reagent in a Teflon Bag. The concentrations of PAN and PPN in the synthesized solutions were quantified by ion chromatography (IC). Further calibration of the GC-ECD for PAN was conducted by in situ photochemical formation of gaseous PAN which was quantified by a $\mathrm{NO}_{x}$ analyzer. The two calibration methods agreed well with each other, and the overall uncertainties for measuring atmospheric PAN were estimated to be $\pm 13 \%$ and $\pm 15 \%$ based on the calibrations of IC and $\mathrm{NO}_{x}$, respectively. The detection limits (three times the signal to noise ratio) for PAN, PPN, and $\mathrm{CCl}_{4}$ were estimated to be 22,36 , and 5 pptv (parts per trillion by volume), respectively. The atmospheric concentrations of these compounds were measured for several days in August in Beijing, and the values obtained in this study were found to be in good agreement with the data reported in the literature for Beijing using other GC-ECD methods.
\end{abstract}

() 2012 Elsevier B.V. All rights reserved.

\section{Introduction}

Peroxyacetyl nitrate (PAN) and its homologues (thereafter referred to PANs, $\mathrm{RC}(\mathrm{O}) \mathrm{OONO}_{2}$ ) are particularly important secondary pollutants formed from photochemical reactions of volatile organic compounds (VOCs) in the presence of $\mathrm{NO}_{x}[1-4]$. These compounds are thermally unstable in the lower troposphere, but are quite stable in the mid-and upper troposphere and can be transported over long distances from the polluted continental regions into the remote troposphere [5]. PAN has been recognized as the most abundant species among PANs. The thermal decomposition of PAN is the primary tropospheric loss process at up to approximately $7 \mathrm{~km}$, above which the photolysis reaction becomes important [6,7]. Singh and Hanst [4] have suggested that PAN acts as a temporary

\footnotetext{
* Corresponding author. Tel.: +86 10 62849125; fax: +8610 62849117 .

** Corresponding author. Tel.: +33 2382576 12; fax: +33 238696004 .

E-mail addresses: yjmu@rcees.ac.cn (Y. Mu), mellouki@cnrs-orleans.fr (A. Mellouki).
}

reservoir for $\mathrm{NO}_{x}$ through the long-range transport and subsequent release of $\mathrm{NO}_{x}$, especially in the lower troposphere where it may control the photochemical production of $\mathrm{O}_{3}$ in the remote marine troposphere. PANs have been also recognized as lachrymators [8], mutagens [9], and phytotoxins [10].

Carbon tetrachloride $\left(\mathrm{CCl}_{4}\right)$, the other species investigated in this work, was often used during the synthesis of chlorofluorocarbons and has been widely used as a solvent for the past chemical processes [11]. Compared to PANs, $\mathrm{CCl}_{4}$ is thermally stable in the troposphere, not subject to photolysis in the troposphere and nonreactive toward the tropospheric oxidants [12]. The lifetime of atmospheric $\mathrm{CCl}_{4}$ extends to several decades [13]. Therefore, the emitted $\mathrm{CCl}_{4}$ can ultimately diffuse into the stratosphere, where it will release $\mathrm{Cl}$ atoms under the intensive ultraviolet sunlight irradiation and participate in the depletion of the stratospheric ozone [14].

The atmospheric pollution levels of PAN, peroxypropionyl nitrate (PPN), and $\mathrm{CCl}_{4}$ are of key concern and are of particular importance in atmospheric chemistry. Several techniques have been developed for measuring these species in the 


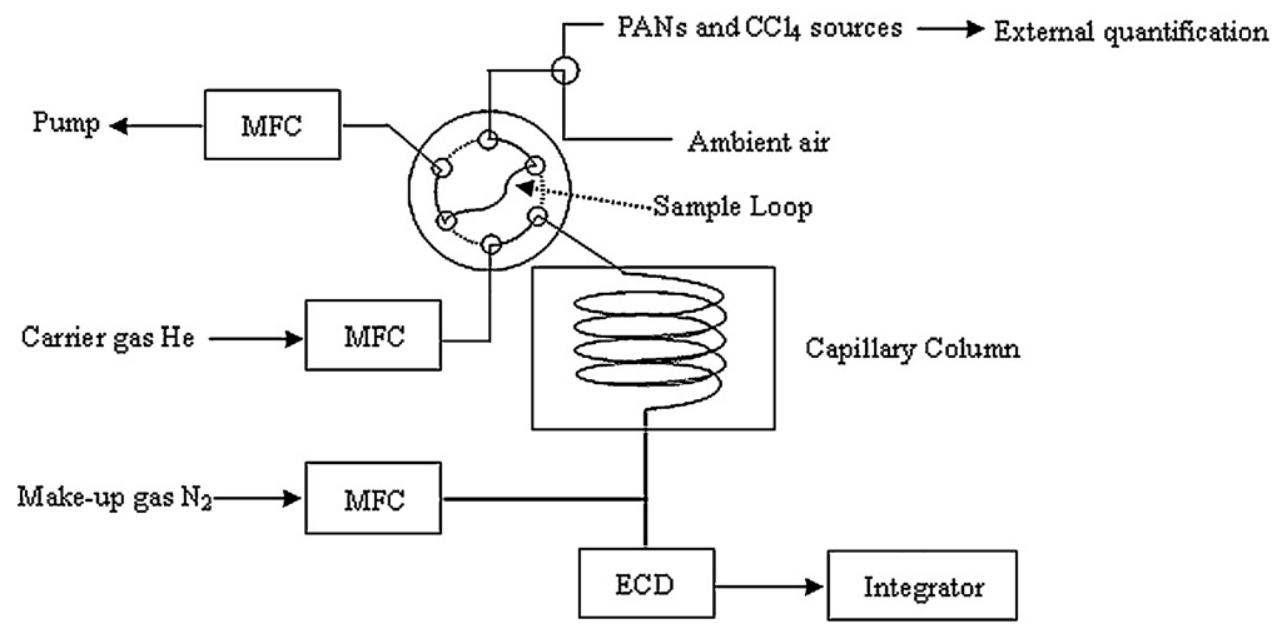

Fig. 1. Schematic diagram of the GC-ECD system. MFC stands for the mass flow controller.

atmosphere, e.g., Fourier transform-infrared spectroscopy (FTIR) [15], gas chromatography-electron capture detection (GC-ECD) [16], thermal dissociation-chemical ion mass spectrometry (TDCIMS) [17], and proton transfer reaction mass spectrometer (PTR-MS) [18]. Because GC-ECD has specific sensitivity and selectivity, it is presently considered to be a good method for the determination of PAN and PPN $[19,20]$ and has been established in the global observation network for $\mathrm{CCl}_{4}[13,21,22]$.

The GC-ECD technique using packed columns was developed for the detection of PAN by Stephens and co-workers [23-26]. However, the authors reported that a sensitivity of $\sim 1$ ppbv (parts per billion by volume) for PAN using a typical sample volume of $2 \mathrm{~mL}$ of air is insufficient for quantifying the trace levels of PAN that are often encountered in the atmosphere. Subsequently, the cryogenic enrichment coupled to GC-ECD technique for measuring atmospheric PANs was developed, and the detection limit could reach several pptv using a sampling volume of several hundred milliliters $[27,28]$. The introduction of capillary gas chromatography has greatly increased the sensitivity of the GC-ECD technique [29-31] and has reduced the need for cryogenically enriched sampling, which can result in extra detection uncertainty because of the thermal instability of PAN and PPN [32].

Although several capillary columns have been tested for the separation of PANs, most of them were only limited to laboratory studies and not used in field applications. Currently, the DB-210 capillary column, which is a high-polarity phase (50\% trifluoropropyl-methyl polysiloxane), is widely used for the direct measurements of atmospheric PANs in various regions and has detection limits of several pptv for a sample air volume of $2 \mathrm{~mL}$ $[16,20,33,34]$. The laboratory studies $[30,32]$ indicated that the non-polar stationary phase DB-1 (100\% dimethylpolysiloxane) is capable of effectively separating PANs, alkyl nitrates and halogenated hydrocarbons. A GC-ECD method developed by Fukui and Doskey [32] using a DB-1 capillary column for separation indicated that the detection limits for PAN and PPN with the enrichment of $50 \mathrm{~mL}$ air could approach $0.15 \mathrm{pptv}$ and $0.43 \mathrm{pptv}$, respectively. However, further field measurements were not performed using this method.

Because of the importance of atmospheric PAN, PPN, and $\mathrm{CCl}_{4}$ and the effective separation capacity of the DB-1 capillary column, a method was developed in this study for directly and simultaneously detecting atmospheric PAN, PPN, and $\mathrm{CCl}_{4}$ using GC-ECD coupled with a DB-1 capillary column. The atmospheric concentrations of PAN, PPN, and $\mathrm{CCl}_{4}$ in a sampling site of Beijing were measured using this method during August 2010.

\section{Experimental}

\subsection{PANs and $\mathrm{CCl}_{4}$ sources}

PAN and PPN were individually synthesized from the acidcatalyzed nitration of the corresponding peroxyacids in dodecane based on the methods described in the literature with slight modifications $[20,35,36]$. The peracetic acid or peroxypropionic acid $(3 \mathrm{~mL})$ was mixed with dodecane $(25 \mathrm{~mL})$, cooled to about $0^{\circ} \mathrm{C}$, and acidified by the sequential addition of concentrated sulfuric acid $(3 \mathrm{~mL})$ and then slowly reacted with concentrated nitric acid $(0.5 \mathrm{~mL})$ added drop by drop. The dodecane layer in the synthesis mixture was separated from the water layer (or acid layer), and washed 2-3 times with $\sim 25 \mathrm{~mL}$ cold deionization water to remove traces of the inorganic acids (such as $\mathrm{H}_{2} \mathrm{SO}_{4}$ and $\mathrm{HNO}_{3}$ ), and dried with anhydrous magnesium sulfate $\left(\mathrm{MgSO}_{4}\right)$, and then stored in a freezer at a temperature below $-20^{\circ} \mathrm{C}$ after being filtered. The concentrations of PAN and PPN in the synthesized solutions were determined using the procedure described in Section 2.3. $\mathrm{CCl}_{4}$ (analytical purity $>99.5 \%$ ) was purchased from Sinopharm Chemical Reagent Company, China.

\subsection{Gas chromatography}

The gaseous PAN, PPN, and $\mathrm{CCl}_{4}$ were analyzed using a modified Hewlett-Packard 5890 gas chromatograph equipped with a ${ }^{63} \mathrm{Ni}$ electron capture detector and a capillary column DB-1 (30 m length, $0.32 \mathrm{~mm}$ ID, $1.0 \mu \mathrm{m}$ film thickness, Agilent Technologies). The schematic diagram of the employed experimental system is shown in Fig. 1. A six-port valve (MGS-4, Shimadzu, Japan) with a sampling loop of $0.5 \mathrm{~mL}$ was connected between the GC carrier gas line and the capillary column DB-1 for sample loading and injection.

\subsection{GC calibration}

The PAN and PPN concentrations in the synthesized solutions were first quantified using ion chromatography (IC) based on the quantitative conversion of PAN and PPN to $\mathrm{NO}_{2}{ }^{-}$under hydrolysis in alkaline solution [29]. The hydrolysis was conducted by dissolving $10 \mu \mathrm{L}$ of the synthesized PAN or PPN solution in $10 \mathrm{~mL}$ of a sodium hydroxide solution $(10 \mathrm{mM})$. The IC analysis was performed using an ICS-2000 ion chromatograph (Dionex Corporation, CA, USA) equipped with a Dionex-AS19 separation column with a $\mathrm{KOH}$ solution $(20 \mathrm{mM})$ flow rate of $1 \mathrm{~mL} \mathrm{~min}^{-1}$.

The aliquot amount of the synthesized PAN and PPN solutions and the $\mathrm{CCl}_{4}$ reagent were injected into a $10 \mathrm{~L}$ Teflon bag filled with 
high-purity nitrogen (99.999\%) using a microsyringe to obtain a gaseous mixture in ppbv level. The gaseous mixture was introduced into the $0.5 \mathrm{~mL}$ loop and then injected into the GC by switching the six-port valve (Fig. 1). To ensure the reliability of the calibration, another method was also performed to further calibrate the PAN signal in the GC-ECD; this method was the in situ formation of PAN via the photochemical reaction of a gaseous mixture containing excess acetone with NO (the ratio of acetone to NO was $\sim 200: 1$ ) in a $150 \mathrm{~L}$ Teflon bag irradiated using low-pressure mercury lamps which have a principal emission wavelength of $253.7 \mathrm{~nm}$. NO can be completely converted to PAN in the presence of excess acetone after 5 min of irradiation [37]. The exact $\mathrm{NO}_{x}$ concentration in the gaseous mixture was quantified using a Model $42 \mathrm{i} \mathrm{NO} \mathrm{N}_{x}$ Analyzer (Thermo Scientific, USA), and the formed PAN was simultaneously detected using GC-ECD.

\subsection{Field measurements}

The developed method was used for field measurements in August 2010 on the sixth floor of the Environmental Technological building ( $20 \mathrm{~m}$ above the ground level) in the Research Center for Eco-Environmental Sciences (RCEES), which is located in the north of Beijing city $\left(39.8^{\circ} \mathrm{N}, 116.5^{\circ} \mathrm{E}\right)$ between the 4 th and 5 th ring roads.

Samples of ambient air were introduced into the GC loop using a minipump (NMP830KNDC, KNF Inc.) and a Teflon tube (3 mm $\mathrm{OD}, 6 \mathrm{~m}$ length) at a flow rate of $\sim 1.5 \mathrm{~L} \mathrm{~min}^{-1}$. Each sampling time was $20 \mathrm{~s}$, and the pressure was equilibrated for $5 \mathrm{~s}$ by turning the pump power off; then, the six-port valve was switched for GC-ECD analysis. The analyzing frequency was set to $30 \mathrm{~min}$.

\section{Results and discussion}

\subsection{Quantification of the concentrations of PAN and PPN in the synthesized solutions}

The hydrolysis of PAN (or PPN) in alkaline solution can quantitatively form $\mathrm{CH}_{3} \mathrm{COO}^{-}$(or $\mathrm{CH}_{3} \mathrm{CH}_{2} \mathrm{COO}^{-}$) and $\mathrm{NO}_{2}^{-}$(see Eq. (1) below).

$$
\begin{aligned}
& \mathrm{CH}_{3} \mathrm{COO}_{2} \mathrm{NO}_{2}\left(\mathrm{CH}_{3} \mathrm{CH}_{2} \mathrm{COO}_{2} \mathrm{NO}_{2}\right)+2 \mathrm{OH}^{-} \\
& \quad \rightarrow \mathrm{CH}_{3} \mathrm{COO}^{-}\left(\mathrm{CH}_{3} \mathrm{CH}_{2} \mathrm{COO}^{-}\right)+\mathrm{NO}_{2}^{-}+\mathrm{O}_{2}+\mathrm{H}_{2} \mathrm{O}
\end{aligned}
$$

Part of the formed $\mathrm{NO}_{2}{ }^{-}$can be further oxidized to $\mathrm{NO}_{3}{ }^{-}$under weak alkaline conditions [29]. To avoid the further oxidation of the formed $\mathrm{NO}_{2}{ }^{-}$, a strong alkaline solution of $\mathrm{NaOH}(\mathrm{pH} \approx 12)$ was used for hydrolysis in this study. A typical ion chromatogram for the hydrolysis of the synthesized PAN solution is shown in Fig. 2. There was no $\mathrm{NO}_{3}{ }^{-}$peak, which should appear at approximately $7.5 \mathrm{~min}$, as observed in the chromatogram. Because the $\mathrm{CH}_{3} \mathrm{C}(\mathrm{O}) \mathrm{OOH}$ (or $\mathrm{CH}_{3} \mathrm{CH}_{2} \mathrm{C}(\mathrm{O}) \mathrm{OOH}$ ) used during the synthesis of PAN (or PPN) can remain in the solution [29,35], only $\mathrm{NO}_{2}{ }^{-}$was chosen for the quantification of PAN (or PPN) using the standard $\mathrm{NO}_{2}^{-}$solution. To determine the accuracy of the IC calibration procedure, four hydrolyses of PAN were performed, and the mean concentration of PAN in the synthesized solution was determined to be $39.2 \mu \mathrm{g} \mathrm{mL}^{-1}$ with a relative standard deviation (RSD) of $6.2 \%\left(\sigma_{1}\right)$. Additionally, the mean concentration of PPN in the synthesized solution was determined to be $48.9 \mu \mathrm{g} \mathrm{mL}^{-1}$.

\subsection{Optimizing GC-ECD conditions}

The GC-ECD was first conditioned by heating the column and detector at $250^{\circ} \mathrm{C}$ and $350^{\circ} \mathrm{C}$, respectively for one week. The response of the GC-ECD under the conditions described by Fukui and Doskey [32] was initially tested, and a very small signal was



Fig. 2. Ion chromatogram of a $10 \mu \mathrm{L}$ PAN solution hydrolyzed in $10 \mathrm{~mL}$ of sodium hydroxide solution. The elution sequence is $1 . \mathrm{CH}_{3} \mathrm{COO}^{-}, 2 . \mathrm{Cl}^{-}, 3 . \mathrm{NO}_{2}{ }^{-}$, and $4 . \mathrm{SO}_{4}{ }^{2-}$ (the arrow indicated the retention time of $\mathrm{NO}_{3}{ }^{-}$).

observed by the direct injection of a high concentration of PAN ( $\sim 10$ ppbv) during the early days of the experiment. However, the GC-ECD signal gradually increased, and a maximum, stable value could be obtained after two weeks with frequent injections. After a series of tests, the GC conditions were further optimized as follows: the GC oven and detector temperatures were maintained at $20^{\circ} \mathrm{C}$ and $38^{\circ} \mathrm{C}$, respectively; and the helium carrier gas (99.999\%) and $\mathrm{N}_{2}$ make-up gas (99.999\%) flow rates were adjusted to $8 \mathrm{~mL} \mathrm{~min}^{-1}$ and $54 \mathrm{mLmin}^{-1}$, respectively. In comparison with the column temperature of $20^{\circ} \mathrm{C}$ used in this study, a serious loss of PANs (approximately 10\%) on the separation column was observed when the column temperature was $30^{\circ} \mathrm{C}$ as used by Fukui and Doskey [32]. The cryogenic enrichment method developed by Fukui and Doskey [32] was initially used in this study but finally halted due to the strong influence of oxygen, a very large relative standard deviation (greater than 50\%), and the complexity of the procedure. Because the GC-ECD method is very sensitive to oxygen, the influence of the strong, broad oxygen peak on the quantification of PAN and $\mathrm{CCl}_{4}$ was also observed when a loop greater than $1 \mathrm{~mL}$ was used; therefore, a $0.5 \mathrm{~mL}$ loop was used in this study.

To avoid the influence of back pressure in the GC loop caused by sampling via the minipump (NMP830KNDC, KNF Inc.) with a flow rate of $\sim 1.5 \mathrm{~L} \mathrm{~min}^{-1}$, both the sampling time and equilibration time with the pump powered off were tested. The GC-ECD signal was observed to be stable when the sampling time and equilibration time were greater than $20 \mathrm{~s}$ and $5 \mathrm{~s}$, respectively. There was not a significant difference between the positive pressure injection using a syringe and the negative pressure sampling using the pump with the same equilibration time.

\subsection{Preparing calibration gaseous mixtures}

Because of the conflicting influences of temperature on the evaporation and thermal decomposition rates of PAN and PPN, their gaseous mixtures were prepared under two temperatures of $10^{\circ} \mathrm{C}$ and $25^{\circ} \mathrm{C}$; then, their responses were periodically measured using GC-ECD to optimize the calibration time. As shown in Fig. 3, the PAN and PPN signals increased sharply after injecting the PAN and PPN solutions into the bags and then gradually decreased after their maximum signals were obtained. Theoretically, the maximum signals correspond to the responses of the closest actual concentrations prepared for PAN and PPN and should be used for the GC-ECD calibration. The appearance times and the values of the maximum signals of PAN and PPN at $25^{\circ} \mathrm{C}$ were much faster and larger, 


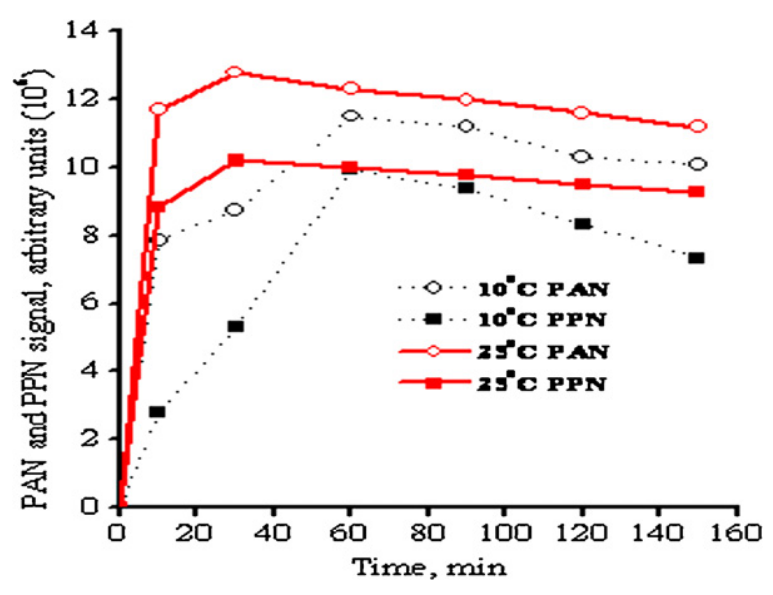

Fig. 3. The responses of GC-ECD to gas phase PAN and PPN vs. volatilization time at temperatures of $10^{\circ} \mathrm{C}$ and $25^{\circ} \mathrm{C}$. The dotted line with open cycles represents PAN at $10^{\circ} \mathrm{C}$. The dotted line with solid squares represents PPN at $10^{\circ} \mathrm{C}$. The solid line with open cycles represents PAN at $25^{\circ} \mathrm{C}$. The solid line with solid squares represents $\mathrm{PPN}$ at $25^{\circ} \mathrm{C}$ (in color on the Web and in black-and-white in print).

respectively, than those at $10^{\circ} \mathrm{C}$, and the decay rates after the maximum signals were slower at $25^{\circ} \mathrm{C}$ than at $10^{\circ} \mathrm{C}$. This phenomenon was contrary to the thermal decomposition behavior of PAN and PPN, but was in good agreement with the results of Meyrahn et al. [37] in a glass container and Helmig et al. [29] in a Tedlar bag, who explained such phenomena as the strong wall-catalysis/absorption at low temperature. Therefore, the GC-ECD was calibrated in this study via the volatilization of the PAN and PPN solutions for $30 \mathrm{~min}$ at $25^{\circ} \mathrm{C}$. The RSD of the GC peak area for PAN from repetitions of volatilization $(n=7)$ was $10.4 \%\left(\sigma_{2}\right)$. Note that the PAN and PPN concentrations were very stable when the gas mixtures prepared in the Teflon bags were transferred into $100 \mathrm{~mL}$ glass syringes. The precisions of the GC-ECD method for PAN and PPN were determined to be $2.9 \%\left(\sigma_{3}\right)$ and $4.5 \%$, respectively, based on seven injections of each gas mixture from $100 \mathrm{~mL}$ syringes. Therefore, the total uncertainty of the IC calibration procedure for PAN was estimated to be $\pm 13 \%(\sigma)$ based on the propagation of error according to Eq. (2):

$\sigma= \pm \sqrt{\sigma_{1}^{2}+\sigma_{2}^{2}+\sigma_{3}^{2}}$.

The volatilization of $\mathrm{CCl}_{4}$ in the Teflon bag was observed to be too slow at room temperature, and the temperature for the volatilization of $\mathrm{CCl}_{4}$ was finally set at $50^{\circ} \mathrm{C}$, where the maximum plateau appears at approximately $10 \mathrm{~min}$. The RSD of the GC peak area for $\mathrm{CCl}_{4}$ from seven injections was approximately $5 \%$.

\subsection{GC calibration with in situ photochemical formation}

The main reactions that occur from the ultraviolet irradiation of the gaseous mixture of acetone and NO in the air, which result in the formation of PAN, are shown in the reactions below:

$$
\begin{aligned}
& \mathrm{CH}_{3} \mathrm{C}(\mathrm{O}) \mathrm{CH}_{3} \stackrel{h \nu(\lambda \approx 254 \mathrm{~nm})}{\longrightarrow} \mathrm{CH}_{3} \mathrm{C}(\mathrm{O})+\mathrm{CH}_{3} \\
& \mathrm{CH}_{3} \mathrm{C}(\mathrm{O})+\mathrm{O}_{2} \rightarrow \mathrm{CH}_{3} \mathrm{C}(\mathrm{O}) \mathrm{OO} \\
& \mathrm{CH}_{3} \mathrm{C}(\mathrm{O}) \mathrm{OO}+\mathrm{NO} \rightarrow \mathrm{CH}_{3} \mathrm{C}(\mathrm{O}) \mathrm{O}+\mathrm{NO}_{2} \\
& \mathrm{CH}_{3} \mathrm{C}(\mathrm{O}) \mathrm{OO}+\mathrm{NO}_{2} \rightleftharpoons \mathrm{CH}_{3} \mathrm{C}(\mathrm{O}) \mathrm{OONO}_{2}(\mathrm{PAN})
\end{aligned}
$$

The large excess of acetone relative to NO in the mixture favored the complete conversion of $\mathrm{NO}_{x}$ to PAN [37]. Both PAN and $\mathrm{NO}_{2}$ have been verified to be efficiently converted ( 98\%) to $\mathrm{NO}$ in a molybdenum-containing catalytic converter of $\mathrm{NO}_{x}$

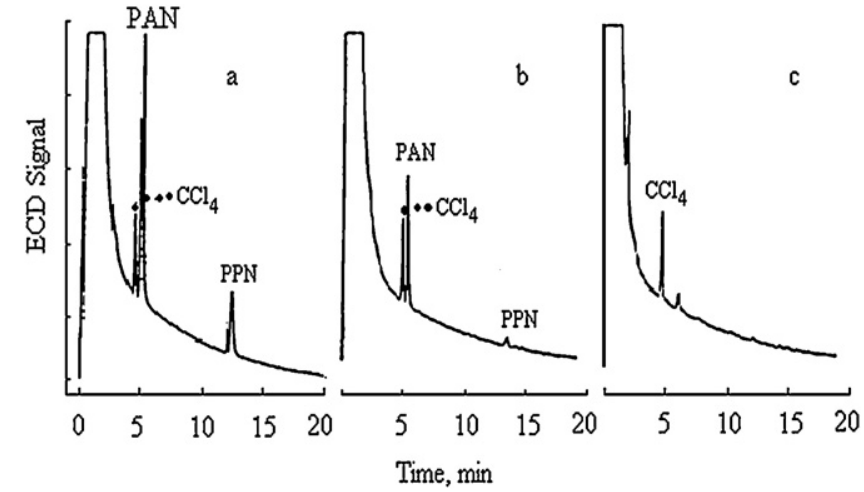

Fig. 4. Gas chromatograms of the standard gas of PANs and $\mathrm{CCl}_{4}(\mathrm{a})$, ambient air (b) and heated ambient air (c).

analyzer at $325^{\circ} \mathrm{C}$, and can be detected by the $\mathrm{NO}_{x}$ analyzer [20]. Because small amount of $\mathrm{NO}_{2}$ must exist in the gas mixture from the equilibrium reaction of PAN and both PAN and $\mathrm{NO}_{2}$ have the same response on the $\mathrm{NO}_{x}$ analyzer, the $\mathrm{NO}_{2}$ value displayed in the $\mathrm{NO}_{x}$ analyzer can only represent the upper limit of the concentration of PAN. However, to date, $\mathrm{NO}_{x}$ analyzer has been widely used for GC-ECD PAN calibration via the in situ photochemical formation of PAN [20,32]. To ensure the reliability of $\mathrm{NO}_{x}$ analyzer calibration method, the PAN concentrations in the photochemical mixtures with different initial NO concentrations were simultaneously measured by using the GC-ECD calibrated with the IC and the $\mathrm{NO}_{x}$ analyzer. Good agreement $\left(\right.$ Slope $\left(\mathrm{PAN}_{\mathrm{NO}_{x}} / \mathrm{PAN}_{\mathrm{IC}}\right)=1.08 \pm 0.04$, Intercept $=-2.65 \pm 1.09$, $\mathrm{SD}=1.56, N=12, R=0.99, P<0.0001)$ between the two values measured by the GC-ECD and $\mathrm{NO}_{x}$ analyzer was found in the concentration range of $0-50$ ppbv.

The photochemical generation of PAN from the irradiation of fixed concentrations of acetone and NO (acetone 4 ppmv, NO 20 ppbv) for 5 min was conducted seven times; the RSD of the PAN signals measured using the GC-ECD and of the PAN concentrations measured using the $\mathrm{NO}_{x}$ analyzer were $13.8 \%$ and $5.0 \%$, respectively. According to Eq. (2), the total uncertainty was estimated to be $\pm 15 \%$ based on the calibration of $\mathrm{NO}_{x}$ analyzer with the in situ photochemical generation of PAN.

A good linear correlation between the GC-ECD signals and the PAN concentrations ( $0-15.8 \mathrm{ppbv})$ was also observed $(R=0.999$, $P<0.0001)$. Because linear correlations between the GC-ECD signals and PPN and the $\mathrm{CCl}_{4}$ concentrations have been well documented in the literature $[20,27]$, no further investigations were conducted in this study. The detection limits (three times the signal to noise ratio) in this study were estimated to be 22 pptv for PAN, 36 pptv for PPN, and 5 pptv for $\mathrm{CCl}_{4}$, respectively.

\subsection{Identification of atmospheric $\mathrm{CCl}_{4}, \mathrm{PAN}$ and $\mathrm{PPN}$}

The typical gas chromatograms of the prepared gaseous mixture of $\mathrm{CCl}_{4}, \mathrm{PAN}$, and PPN and the ambient air with or without heating, are shown in Fig. 4. As seen in Fig. 4a, the capillary DB-1 column can effectively separate the three pollutants with retention times of $5.38 \mathrm{~min}, 5.75 \mathrm{~min}$, and $13.38 \mathrm{~min}$, respectively. There were also three evident peaks corresponding to the retention times of the prepared gaseous mixture in the ambient air (Fig. $4 \mathrm{~b}$ ). To determine if there were any influences of other co-eluents such as 2-propyl nitrate and 2-butyl nitrate in the air on measuring PAN and PPN [30], the ambient air was re-analyzed using the GC-ECD after being heated to approximately $80^{\circ} \mathrm{C}$. The disappearances of PAN and PPN (Fig. 4c) in the air sample after heating indicated 
Table 1

Comparison with available GC-ECD methods for atmospheric PAN and PPN.

\begin{tabular}{|c|c|c|c|c|c|c|}
\hline Separation column & Injection manner & Injection quantity & Species & $\begin{array}{l}\text { Detection } \\
\text { limits }^{\mathrm{a}} \text { (pptv) }\end{array}$ & Uncertainty & Ref. \\
\hline \multirow[t]{2}{*}{ Carbowax 400} & \multirow{2}{*}{ Cryogenic enrichment } & \multirow{2}{*}{$500 \mathrm{~mL}$} & PAN & 2 & \multirow{2}{*}{ Not reported } & \multirow{2}{*}{ [28] } \\
\hline & & & PPN & 2 & & \\
\hline \multirow[t]{2}{*}{ HP-1 } & \multirow[t]{2}{*}{ Cryogenic enrichment } & \multirow[t]{2}{*}{$80 \mathrm{~mL}$} & PAN & 8 & \multirow[t]{2}{*}{$15 \% \mathrm{~b}$} & \multirow[t]{2}{*}{ [38] } \\
\hline & & & PPN & 20 & & \\
\hline \multirow[t]{2}{*}{ DB-1 } & \multirow[t]{2}{*}{ Cryogenic enrichment } & \multirow[t]{2}{*}{$50 \mathrm{~mL}$} & PAN & 0.15 & $5.6 \% c$ & \multirow[t]{2}{*}[32]{} \\
\hline & & & PPN & 0.43 & $19 \%{ }^{\mathrm{c}}$ & \\
\hline \multirow[t]{3}{*}{ DB-1 } & \multirow[t]{3}{*}{ Direct injection } & \multirow[t]{3}{*}{$0.5 \mathrm{~mL}$} & $\mathrm{CCl}_{4}$ & 5 & $5 \% c$ & \multirow[t]{3}{*}{ This study } \\
\hline & & & PAN & 22 & $\pm 15 \%$ & \\
\hline & & & PPN & 36 & $\pm 15 \%$ & \\
\hline \multirow[t]{2}{*}{ DB-210 } & \multirow[t]{2}{*}{ Direct injection } & \multirow[t]{2}{*}{$2 \mathrm{~mL}$} & PAN & 5 & $15-20 \%$ & \multirow[t]{2}{*}[20]{} \\
\hline & & & PPN & 6.2 & & \\
\hline \multirow[t]{2}{*}{ Rtx-200 } & \multirow[t]{2}{*}{ Direct injection } & \multirow[t]{2}{*}{ Not reported } & PAN & 5 & $\pm 15 \%$ & \multirow[t]{2}{*}[44]{} \\
\hline & & & PPN & 5 & $\pm 20 \%$ & \\
\hline
\end{tabular}

\footnotetext{
a Detection limit $=$ three times the signal to noise ratio.

b Instrument precision.

c Estimated uncertainty.
}

that the interferences of co-eluents with ambient PAN and PPN measurements were likely negligible [20].

\subsection{Comparison with available GC-ECD methods for atmospheric PAN and PPN}

The developed method is compared to the available GC-ECD methods in Table 1. Considering the injection amount of air, the detection limit for PAN in this work is in good agreement with the two GC-ECD methods that employ direct injection, but somewhat higher for PPN because of its longer retention time in our GC column. The extremely low detection limits of the cryogenic enrichment method developed by Fukui and Doskey [32] could not be achieved in our hands. In addition to the losses of PANs using the higher column temperature (as mentioned in Section 3.2), the thermal decomposition of PANs during the thermal desorption procedure would also cause serious losses of PANs. Furthermore, the detection limits reported in another cryogenic enrichment study [38] employing similar injection quantities ( $80 \mathrm{~mL}$ vs. $50 \mathrm{~mL}$ ) and the same stationary phase were fifty-fold greater than those reported in Ref. [32].

\subsection{Field measurements}

Field measurements were conducted for 5 days during August in Beijing, and the responses of GC-ECD for PAN were calibrated every day with $\mathrm{NO}_{x}$ analyzer based on the method of photochemical formation. PAN, PPN, and $\mathrm{CCl}_{4}$ could be detected in every sample during the measuring days, as shown in Fig. 5. The diurnal variations of PAN and PPN exhibited maximum values in the afternoon and minimal values during early morning and midnight, confirming that they were secondary products of photochemical reactions. The average and maximum concentrations of PAN were $3.10 \pm 1.65 \mathrm{ppbv}(n=118)$ and $6.99 \mathrm{ppbv}$ and of PPN were $0.48 \pm 0.32 \mathrm{ppbv}$ and $1.32 \mathrm{ppbv}$, respectively. Our results of PAN and PPN are comparable with the values recently measured by the National Oceanic and Atmospheric Administration (NOAA) (Boulder, CO, Beijing) using online GC-ECD [39-41]. The average and maximum concentration ranges reported in these studies were 3.79-5 and 2.49-17.8 ppbv, respectively, for PAN and 0.23-0.56 and 0.5-2.48 ppbv, respectively, for PPN. The diurnal variation patterns of PAN and PPN were similar, and the quantification correlation could be derived from the linear regression between them as PPN $[\mathrm{ppbv}]=(0.183 \pm 0.005) * \mathrm{PAN}[\mathrm{ppbv}]-(0.088 \pm 0.019)[\mathrm{ppbv}]$ $(N=118, R=0.95, P<0.0001)$.
Although PAN and PPN are both formed in the atmosphere through photochemical processes, their VOCs precursors are different. The precursors for PAN (ethane, butane, isoprene, and acetone, etc.) have been reported to be emitted from both anthropogenic and biogenic sources, whereas the precursors for PPN (propane and 1-butene, etc.) are predominantly from anthropogenic sources $[42,43]$. Therefore, the ratio of PPN to PAN has been used as an indicator for evaluating the relative importance of anthropogenic and biogenic sources for contributing to atmospheric PANs. With extensive field measurements, Roberts et al. $[16,44]$ concluded that the formation of PANs was dominated by anthropogenic sources when the PPN/PAN ratio was between $13.5 \%$ and $17.2 \%$ and was dominated by biogenic sources when the ratio was less than $10 \%$. The average PPN/PAN ratio in this study was $14.7 \%$, which suggested that anthropogenic sources were prevailing during the PANs sampling period in Beijing.

In contrast, the diurnal variations of $\mathrm{CCl}_{4}$ were irregular, which might be ascribed to strong influence of local unidentified sources. The $\mathrm{CCl}_{4}$ concentration of $122.8 \pm 96.7$ (mean $\pm \mathrm{SD}$ ) pptv was comparable to the concentration of $108.0 \pm 12.5$ pptv observed by Sun et al. [45] in August 2009 in Beijing and the value of $114 \pm 11$ pptv reported by Barletta et al. [46] from measurements in 45 cities of China, but was higher than the background values at

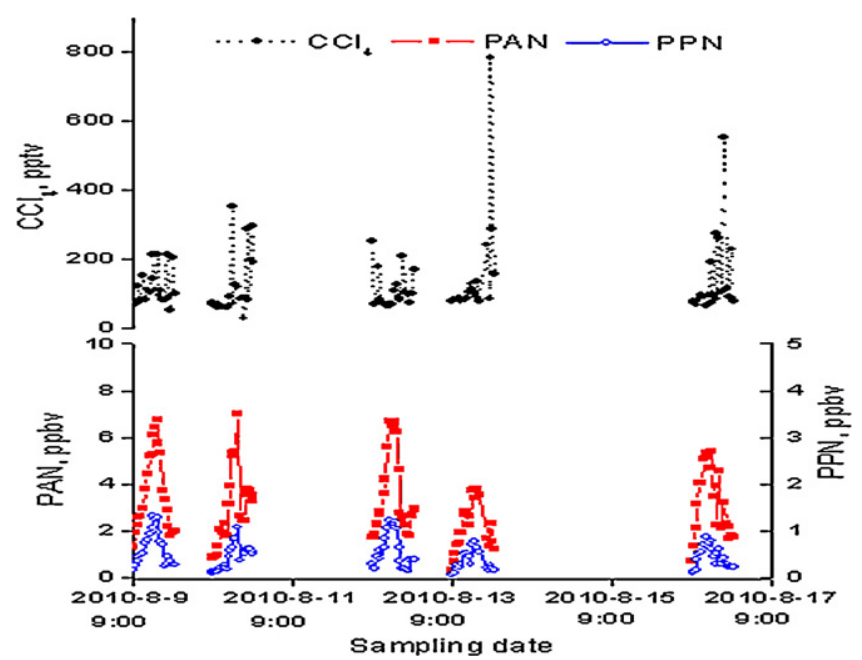

Fig. 5. The diurnal variations of PAN, $\mathrm{PPN}$, and $\mathrm{CCl}_{4}$ on the measuring days in Beijing The dotted line with solid cycles represents $\mathrm{CCl}_{4}$. The solid line with solid squares represents PAN. The solid line with open cycles represents PPN (in color on the Web and in black-and-white in print). 
the Shangdianzi global atmosphere watch station ( $89.4 \pm 0.7 \mathrm{pptv})$ in Beijing [47], Mauna Loa (ca. average 89 pptv in 2010) Hawaii and Antarctic (ca. average 88 pptv in 2010) [48]. Although the use of $\mathrm{CCl}_{4}$ as a cleaning reagent had been banned since 2007 according to the agreements of the Montreal Protocol for China, its usage as a chemical auxiliary should have been phased out in 2010 [49]. In comparison with background stations, the relatively high $\mathrm{CCl}_{4}$ concentration measured implied that $\mathrm{CCl}_{4}$ might be still used as a chemical auxiliary in Beijing during the sampling period.

\section{Conclusions}

A GC-ECD method was developed for directly measuring atmospheric $\mathrm{CCl}_{4}$, PAN, and PPN based on two calibrations by the IC and $\mathrm{NO}_{x}$ analyzer. The detection limits of the GC-ECD for $\mathrm{CCl}_{4}, \mathrm{PAN}$, and PPN could reach 5,22 , and $36 \mathrm{pptv}$, respectively. The overall uncertainties in the GC-ECD measurements of PAN were estimated to be $\pm 13 \%$ and $\pm 15 \%$ based on the uncertainties of calibrations via the IC and $\mathrm{NO}_{x}$ analyzer, respectively. Field measurements were conducted using the GC-ECD method for several days in Beijing during August 2010, leading to values in line with previously reported values.

\section{Acknowledgments}

This work was financially supported by the Chinese National Natural Science Foundation (41075094, 21177140, and 40830101), National Basic Research and the Development Program 973 (2010CB732304), and the Special Fund for Environmental Research in the Public Interest (201009001). The authors are grateful to the editor and the anonymous reviewers for the valuable comments and careful corrections.

\section{References}

[1] A.C. Aikin, J.R. Herman, E.J. Maier, C.J. Mcquillan, J. Geophys. Res.: Oc. Atmos. 87 (1982) 3105.

[2] W.A. Lonneman, J.J. Bufalini, R.L. Seila, Environ. Sci. Technol. 10 (1976) 374.

[3] H.B. Singh, Environ. Sci. Technol. 21 (1987) 320.

[4] H.B. Singh, P.L. Hanst, Geophys. Res. Lett. 8 (1981) 941.

[5] R.E. Honrath, A.J. Hamlin, J.T. Merrill, J. Geophys. Res.: Atmos. 101 (1996) 29335

[6] R.K. Talukdar, J.B. Burkholder, A.M. Schmoltner, J.M. Roberts, R.R. Wilson, A.R Ravishankara, J. Geophys. Res.: Atmos. 100 (1995) 14163.

[7] N. Tsalkani, A. Mellouki, G. Poulet, G. Toupance, G. Lebras, J. Atmos. Chem. 7 (1988) 409.

[8] A.P. Altshuller, J. Air Pollut. Control Assoc. 28 (1978) 594.

[9] P.B. Shepson, T.E. Kleindienst, E.O. Edney, C.M. Nero, L.T. Cupitt, L.D. Claxton, Environ. Sci. Technol. 20 (1986) 1008.

[10] O. Taylor, J. Air Pollut. Control Assoc. 19 (1969) 347.

[11] A.P. Altshuller, Environ. Sci. Technol. 10 (1976) 596.
[12] S.P. Sander, J. Abbatt, J.R. Barker, J.B. Burkholder, R.R. Friedl, D.M. Golden, R.E. Huie, C.E. Kolb, M.J. Kurylo, G.K. Moortgat, Jet Propulsion Laboratory, 2011, Publication 10-6.

[13] J.D. Happell, M.P. Roche, Geophys. Res. Lett. 30 (2003) 1088.

[14] M.J. Molina, F.S. Rowland, Nature 249 (1974) 811.

[15] E. Tuazon, R. Graham, A. Winer, R. Easton, J. Pitts Jr., P. Hanst, Atmos. Environ. $12(1978) 865$.

[16] J.M. Roberts, J. Williams, K. Baumann, M.P. Buhr, P.D. Goldan, J. Holloway, G. Hubler, W.C. Kuster, S.A. McKeen, T.B. Ryerson, M. Trainer, E.J. Williams, F.C. Fehsenfeld, S.B. Bertman, G. Nouaime, C. Seaver, G. Grodzinsky, M. Rodgers, V.L. Young, J. Geophys. Res.: Atmos. 103 (1998) 22473.

[17] D.L. Slusher, L.G. Huey, D.J. Tanner, F.M. Flocke, J.M. Roberts, J. Geophys. Res. 109 (2004) D19315.

[18] A. Hansel, A. Wisthaler, Geophys. Res. Lett. 27 (2000) 895

[19] D.D. Parrish, F.C. Fehsenfeld, Atmos. Environ. 34 (2000) 1921.

[20] J. Williams, J.M. Roberts, S.B. Bertman, C.A. Stroud, F.C. Fehsenfeld, K. Baumann, M.P. Buhr, K. Knapp, P.C. Murphy, M. Nowick, E.J. Williams, J. Geophys. Res.: Atmos. 105 (2000) 28943.

[21] R. Derwent, P. Simmonds, S. O‘doherty, D. Ryall, Atmos. Environ. 32 (1998) 3689.

[22] P. Simmonds, D. Cunnold, F. Alyea, C. Cardelino, A. Crawford, R. Prinn, P. Fraser R. Rasmussen, R. Rosen, J. Atmos. Chem. 7 (1988) 35.

[23] E.F. Darley, K.A. Kettner, E.R. Stephens, Anal. Chem. 35 (1963) 589.

[24] E.R. Stephens, P.L. Hanst, R.C. Doerr, W.E. Scott, Ind. Eng. Chem. 48 (1956) 1498.

[25] E.R. Stephens, J. Chem. Educ. 50 (1973) 351.

[26] E.R. Stephens, J. Pitts, R. Metcalfe, Adv. Environ. Sci. 1 (1969) 119.

[27] N. Moschonas, S. Glavas, J. Chromatogr. A 902 (2000) 405.

[28] I. Watanabe, M. Nakanishi, J. Tomita, S. Hatakeyama, K. Murano, H. Mukai, H. Bandou, Environ. Pollut. 102 (1998) 253.

[29] D. Helmig, J. Muller, W. Klein, Atmos. Environ. 23 (1989) 2187.

[30] J.M. Roberts, R.W. Fajer, S.R. Springston, Anal. Chem. 61 (1989) 771.

[31] N. Roumelis, S. Glavas, Anal. Chem. 61 (1989) 2731.

[32] Y. Fukui, P.V. Doskey, J. High Resol. Chromatogr. 21 (1998) 201

[33] H.B. Singh, D. Herlth, D. Ohara, K. Zahnle, J.D. Bradshaw, S.T. Sandholm, R. Talbot G.L. Gregory, G.W. Sachse, D.R. Blake, S.C. Wofsy, J. Geophys. Res.: Atmos. 99 (1994) 1821.

[34] J. Williams, J. Roberts, F. Fehsenfeld, S. Bertman, M. Buhr, P. Goldan, G. Hübler, W. Kuster, T. Ryerson, M. Trainer, Geophys. Res. Lett. 24 (1997) 1099.

[35] J.S. Gaffney, R. Fajer, G.I. Senum, Atmos. Environ. 18 (1984) 215.

[36] T. Nielsen, A.M. Hansen, E.L. Thomsen, Atmos. Environ. 16 (1982) 2447.

[37] H. Meyrahn, G. Helas, P. Warneck, J. Atmos. Chem. 5 (1987) 405

[38] S. Glavas, N. Moschonas, Atmos. Environ. 35 (2001) 5467.

[39] Y. Guang, J.B. Zhang, B. Wang, Acta Sci. Nat. Univ. Pekin. 45 (2009) 7 (in Chinese).

[40] Z. Xu, J. Zhang, G. Yang, M. Hu, Atmos. Chem. Phys. Discuss. 11 (2011) 10265.

[41] B. Wang, J.B. Zhang, Environ. Sci. 28 (2007) 6 (in Chinese).

[42] E. Grosjean, D. Grosjean, L.F. Woodhouse, Environ. Sci. Technol. 35 (2001) 4007.

[43] J.M. Roberts, F. Flocke, G. Chen, J. de Gouw, J.S. Holloway, G. Hubler J.A. Neuman, D.K. Nicks, J.B. Nowak, D.D. Parrish, T.B. Ryerson, D.T. Sueper, C. Warneke, F.C. Fehsenfeld, J. Geophys. Res.: Atmos. 109 (2004) D23S21.

[44] J.M. Roberts, F. Flocke, C.A. Stroud, D. Hereid, E. Williams, F. Fehsenfeld, W. Brune, M. Martinez, H. Harder, J. Geophys. Res.: Atmos. 107 (2002) D21.

[45] X.Z. Sun, D. Wan, Y.H. Shi, Res. Environ. Sci. 23 (2010) 674 (in Chinese)

[46] B. Barletta, S. Meinardi, I.J. Simpson, F. Sherwood Rowland, C.Y. Chan, X. Wang, S. Zou, L.Y. Chan, D.R. Blake, Atmos. Environ. 40 (2006) 7706.

[47] B. Yao, L. Zhou, Z. Fang, Acta Sci. Circumstant. 30 (2010) 2377 (in Chinese)

[48] http://gaw.kishou.go.jp/cgi-bin/wdcgg/catalogue.cgi

[49] P.S. Zurer, Chem. Eng. News 73 (1995) 25. 